\title{
Associations between C-Reactive Protein and Apolipoproteins, Lipoprotein (a) and Conventional Serum Lipids in Outpatients: Correlations and Time Trends
}

\author{
Christian Löwbeer ${ }^{1,2^{*}}$, Lena Mårtensson'1, Elisabeth Berg' ${ }^{3}$, Hans Wallinder1 \\ ${ }^{1}$ Department of Clinical Chemistry, Aleris Medilab, Täby, Sweden \\ ${ }^{2}$ Division of Clinical Chemistry, Department of Laboratory Medicine, Karolinska Institutet, Stockholm, Sweden \\ ${ }^{3}$ Medical Statistics Unit, Department of Learning, Informatics, Management and Ethics, Karolinska Institutet, \\ Stockholm, Sweden \\ Email: ${ }^{*}$ christian.lowbeer@aleris.se
}

Received 17 March 2015; accepted 25 May 2015; published 28 May 2015

Copyright (C) 2015 by authors and Scientific Research Publishing Inc.

This work is licensed under the Creative Commons Attribution International License (CC BY). http://creativecommons.org/licenses/by/4.0/

(c) (i) Open Access

\section{Abstract}

Background: Correlations between CRP and serum lipids are weak, and there are conflicting and incomplete results in the literature. The aim of the present study was to clarify the strength and independence of relationships between CRP and serum lipids in outpatients. Methods: Inclusion criteria were outpatients where all the following analyses were requested in clinical routine: high sensitivity CRP, total cholesterol, triglycerides, LDL-cholesterol, HDL-cholesterol, ApoB, ApoA-1 and Lp(a). Data for patients meeting the above criteria during a period of six years (2004-2010) were copied from Aleris Medilab's Laboratory Information System to the software Statistica. Basic statistics and correlations were calculated for 2771 patients. In patients with two $(n=959)$ or more sampling times changes over time were calculated. The study was a quality assurance project without access to patient files. Results: Median age was 59 years and median serum CRP concentration was $1.5 \mathrm{mg} / \mathrm{L}$. The strongest correlations (Spearman R) were seen between CRP and triglycerides (0.25), ApoB/ApoA-1 ratio (0.21) and HDL-cholesterol (-0.18). Stepwise regression analysis showed that $A p o B$, total cholesterol, log triglycerides and $\log \operatorname{Lp}(\mathrm{a})$ together explained $8 \%$ of the variation in log CRP. Unfavourable time trends for CRP and triglycerides counteracted a significant decrease in LDL-cholesterol and total cholesterol. Conclusion: In a large cohort of outpatients CRP showed stronger correlation with triglycerides and ApoB/ApoA-1 ratio than with LDLcholesterol and Lp(a). LDL-cholesterol concentrations changed favorably over time whereas CRP and triglycerides did not.

\footnotetext{
${ }^{*}$ Corresponding author.
} 
Keywords

CRP, Cholesterol, LDL, HDL, ApoB, ApoA-1, Triglycerides, Lp(a), Outpatients, Risk Factors

\section{Introduction}

C-reactive protein (CRP) is an acute-phase protein that is a sensitive and dynamic marker of inflammation [1]. Data from a large number of studies have shown a significant association between elevated serum or plasma concentrations of CRP and the risk of cardiovascular disease, and concentrations $<1,1-3$ and $>3 \mathrm{mg} / \mathrm{L}$ are used clinically to suggest lower, moderate, and higher relative risk of cardiovascular disease (CVD) [2]. However, it is still debatable whether inflammation is an important independent risk factor for CVD, or just a marker of traditional risk factors like aging, smoking, obesity, elevated triglycerides and low density lipoprotein cholesterol (LDL-cholesterol) [3]. CRP and serum lipids are widely used in preventive medicine as risk markers for CVD. However, correlations between CRP and serum lipids are weak and there are conflicting and incomplete results in the literature. Ethnicity and gender may also play a role in selected populations, and the association of CRP with lipid parameters is not clear at the time [4]. Since CRP may be used for risk estimation in patients at moderate CVD risk [5] and in people at intermediate CVD risk [6], it is crucial to clarify associations between CRP concentrations and serum lipids in relevant patient cohorts. Bioinformatics concerned with large databases of analyte concentrations from our routine laboratory data information management systems (LIMS) is underused. By using statistics and mathematics to continuously evaluate data from routine health care we can use this huge mass of interesting data to increase our knowledge about associations between different biomarkers and to explore time trends in populations. To the best of our knowledge, there are no previous studies comparing serum CRP concentrations with a complete lipid panel including conventional lipids, apolipoproteins, and lipoprotein (a) (Lp(a)) in a large cohort of outpatients. The main aim of the present study was to clarify the strength and independence of the relationship between high sensitivity CRP concentrations and a complete panel of serum lipids in an unselected cohort of outpatients in Sweden by using data from our LIMS. Another aim was to explore and visualize time trends in risk marker profile by calculating intra-individual concentration changes over time for all analytes.

\section{Materials and Methods}

The study was a comparison between measured values of serum CRP and serum lipids without access to patient files or other clinical data. Inclusion criteria were consecutive outpatients where all the following analyses were requested and results obtained in clinical routine: CRP measured with a high sensitive assay, total cholesterol, triglycerides, LDL-cholesterol, high density lipoprotein cholesterol (HDL-cholesterol), apolipoprotein B (ApoB), apolipoprotein A-1 (ApoA-1) and Lp(a). A majority (approximately 90\%) of the patients were from primary health care centres in Stockholm County and blood samples were delivered to the central laboratory in Täby by cars. The remaining patients were from other parts of Sweden and blood samples were sent to the central laboratory by mail. Specifications for serum analyses and methods used in the study are shown in Table 1. Measurements were made on fresh serum. Since Friedewald formula was used to calculate LDL-cholesterol, patients with triglycerides $>4.5 \mathrm{mmol} / \mathrm{L}$ were excluded from the study. All data for patients meeting the above criteria during a period of six years (2004-2010), no matter the categories of diseases, were copied and transferred from Aleris Medilab’s Laboratory Information Management System (LIMS) LabMaster (Software Point, Espoo, Finland) to Office Excel (Microsoft Corporation). Data were then transferred to Statistica version 10 (StatSoft, inc., Tusla, USA) for statistical analysis.

\subsection{Ethics Statement}

The study was a quality assurance project within routine health care laboratory practice, in agreement with the laboratory's ISO 15189 accreditation. All laboratory analyses were requested by physicians in clinical routine and serum samples were sent to the laboratory with routine clinical request forms. No extra blood samples and no additional measurements of analytes were preformed for the study and it did not involve any physical inter- 
Table 1. Specifications for serum analyses and methods used in the study.

\begin{tabular}{|c|c|c|c|c|c|c|c|}
\hline Analysis & Method & $\begin{array}{c}\text { Instrument } \\
\text { Abbott }\end{array}$ & $\begin{array}{l}\text { Reagents } \\
\text { fabricate }\end{array}$ & $\begin{array}{l}\text { Calibrator } \\
\text { fabricate }\end{array}$ & $\begin{array}{l}\text { External } \\
\text { control }\end{array}$ & $\begin{array}{c}\text { Measuring } \\
\text { range }\end{array}$ & $\begin{array}{c}\text { Total CV \%/ } \\
\text { Level }\end{array}$ \\
\hline $\begin{array}{l}\text { C-reactive } \\
\text { protein }\end{array}$ & Immuno-chemistry & c16000 & Sentinel & $\begin{array}{l}\text { CRP Calibrator } \\
\text { Sentinel }\end{array}$ & $\begin{array}{l}\text { EQUALIS } \\
\text { Labquality }\end{array}$ & $\begin{array}{l}0.2 \mathrm{mg} / \mathrm{L} \text { to } \\
\text { highest } \\
\text { calibrator in } \\
\mathrm{mg} / \mathrm{L}\end{array}$ & $\begin{array}{l}2.5 \% / 14.4 \\
2.1 \% / 77.7 \\
7.9 \% / 0.62 \\
5.6 \% / 0.98\end{array}$ \\
\hline $\begin{array}{c}\text { Apolipoprotein } \\
\text { A-1 }\end{array}$ & Immuno-chemistry & c16000 & Abbott & $\begin{array}{l}\text { ApoA1/ApoB } \\
\text { Calibrator } \\
\text { Abbott }\end{array}$ & EQUALIS & $\begin{array}{c}0.2 \mathrm{~g} / \mathrm{L} \text { to } \\
\text { highest } \\
\text { calibrator in } \\
\mathrm{g} / \mathrm{L}\end{array}$ & $\begin{array}{l}1.1 \% / 0.98 \\
0.5 \% / 1.96\end{array}$ \\
\hline $\begin{array}{c}\text { Apolipoprotein } \\
\text { B }\end{array}$ & Immuno-chemistry & c16000 & Abbott & $\begin{array}{c}\text { ApoA1/ApoB } \\
\text { Calibrator } \\
\text { Abbott }\end{array}$ & EQUALIS & $\begin{array}{c}0.1 \mathrm{~g} / \mathrm{L} \text { to } \\
\text { highest } \\
\text { calibrator in } \\
\mathrm{g} / \mathrm{L}\end{array}$ & $\begin{array}{l}2.1 \% / 0.72 \\
1.7 \% / 1.31\end{array}$ \\
\hline Lipoprotein (a) & Immuno-turbidimetry & c16000 & Abbott & $\begin{array}{c}\text { Quantia } \\
\text { Lp(a) Standard }\end{array}$ & Labquality & $\begin{array}{l}0.01 \mathrm{~g} / \mathrm{L} \text { to } \\
\text { highest } \\
\text { calibrator in } \\
\mathrm{g} / \mathrm{L}\end{array}$ & $\begin{array}{l}1.7 \% / 0.24 \\
0.8 \% / 0.48\end{array}$ \\
\hline Total cholesterol & Colorimetry & c16000 & Abbott & $\begin{array}{c}\text { MCC1 and MCC2 } \\
\text { Abbott }\end{array}$ & EQUALIS & $\begin{array}{c}0.2-18.3 \\
\mathrm{mmol} / \mathrm{L}\end{array}$ & $\begin{array}{l}0.5 \% / 3.05 \\
0.3 \% / 5.43\end{array}$ \\
\hline HDL-cholesterol & Colorimetry & c16000 & $\begin{array}{l}\text { Ultra } \\
\text { HDL } \\
\text { Abbott }\end{array}$ & $\begin{array}{c}\text { HDL-calibrator } \\
\text { Abbott }\end{array}$ & EQUALIS & $\begin{array}{c}0.13-4.66 \\
\mathrm{mmol} / \mathrm{L}\end{array}$ & $\begin{array}{l}3.1 \% / 0.80 \\
2.2 \% / 1.46\end{array}$ \\
\hline LDL-cholesterol & Calculation $^{*}$ & & & & & & \\
\hline Triglycerides & Colorimetry & c16000 & Abbott & $\begin{array}{c}\text { MCC1 and MCC2 } \\
\text { Abbott }\end{array}$ & EQUALIS & $\begin{array}{c}0.08-16.1 \\
\mathrm{mmol} / \mathrm{L}\end{array}$ & $\begin{array}{l}0.7 \% / 0.95 \\
0.5 \% / 1.50\end{array}$ \\
\hline
\end{tabular}

*The Friedewald formula: LDL-cholesterol = total cholesterol-HDL-cholesterol-(0.45 × Triglycerides) in mmol/L. HDL, high density lipoprotein; LDL, low density lipoprotein.

ventions. There were no methods used intended to physically or mentally influence the persons who were participating. Since data were anonymised, the samples and the results cannot be traced back and connected to any person. The Swedish Ethical Review Act (2003:460), Ethical Review of Research Involving Humans, is therefore not applicable (see section 1 - 4, http://www.epn.se/media/45159/the etical_review_act.pdf). Aleris Medilab therefore hereby certifies that ethical permission and use of informed consent was not required. There is no other legislation in force in Sweden that alters this conclusion. Thus application for ethical vetting of the research was not needed and patients were not informed about the study.

\subsection{Statistics}

Statistics were performed using the analysis softwares Statistica version 10 (StatSoft Inc., Tulsa, OK, USA) and SAS $^{\circledR}$ System 9.1, (SAS Institute Inc., Cary, NC, USA). Univariate correlations between variables were calculated by Spearman rank correlation coefficient R. The strength and independence of the relationships between CRP and lipids were tested by stepwise regression analysis with log CRP as dependent variable and log Lp(a), total cholesterol, log triglycerides, LDL-cholesterol, HDL-cholesterol, ApoA-1, ApoB and ApoB/ApoA-1 ratio as independent variables in the model. Intra-individual concentration changes over time were analysed by random coefficients models. By fitting random coefficients, random variation between the slopes of individual patients is allowed. The method makes also allowance for unequal numbers of observations per patient and unequally spaced observations. The relationship with time was tested for linear and non-linear trends and therefore models using polynomials of time were used. Polynomials of increasing order were added as both fixed effects and random coefficients. Normal distributions were obtained with natural logarithm (log) transformation of the positively skewed variables CRP, triglycerides and $\mathrm{Lp}(\mathrm{a})$. A p-value $<0.05$ was considered to indicate statistical significance.

\section{Results}

Median age was 59 years and median (percentile 25-percentile 75) for CRP was $1.5 \mathrm{mg} / \mathrm{L}$ (0.7 - $3.2 \mathrm{mg} / \mathrm{L}$ ). Basic 
statistics for 2771 outpatients (58\% women) at the first time point of sampling are shown in Table 2. The strongest correlations were seen between CRP and triglycerides, ApoB/ApoA-1 ratio and HDL-cholesterol (Table 3). Stepwise regression analysis showed that ApoB, total cholesterol, log triglycerides and log Lp(a) were independent predictors and together these variables explained $8 \%$ of the variation in log CRP (Table 4). Log CRP concentrations did not change significantly during follow up whereas all the lipids except ApoA-1 (borderline significant) showed significantly changed intra-individual mean values over time (Figure 1). Unfavourable time trends for CRP, triglycerides and ApoA-1 counteracted a significant decrease in LDL-cholesterol and total cholesterol over time.

Table 2. Basic statistics for 2771 outpatients at the first time point of sampling. The number of women was 1595 (58\%) and the number of men 1176 (42\%).

\begin{tabular}{ccccc}
\hline Variable & Unit & Median & Percentile 25 & Percentile 75 \\
Age & years & 59 & 49 & 68 \\
CRP & $\mathrm{mg} / \mathrm{L}$ & 1.5 & 0.70 & 3.2 \\
Lp(a) & $\mathrm{g} / \mathrm{L}$ & 0.11 & 0.05 & 0.30 \\
Total cholesterol & $\mathrm{mmol} / \mathrm{L}$ & 5.5 & 4.7 & 6.3 \\
Triglycerides & $\mathrm{mmol} / \mathrm{L}$ & 1.2 & 0.80 & 1.6 \\
LDL-cholesterol & $\mathrm{mmol} / \mathrm{L}$ & 3.4 & 2.8 & 4.2 \\
HDL-cholesterol & $\mathrm{mmol} / \mathrm{L}$ & 1.4 & 1.1 & 1.7 \\
ApoB & $\mathrm{g} / \mathrm{L}$ & 1.1 & 0.9 & 1.3 \\
ApoA-1 & $\mathrm{g} / \mathrm{L}$ & 1.6 & 1.4 & 1.8 \\
ApoB/ApoA-1 ratio & & 0.71 & 0.56 & 0.87
\end{tabular}

CRP, C-reactive protein; Lp(a), lipoprotein (a); LDL, low density lipoprotein; HDL, high density lipoprotein; ApoB; apolipoprotein B; ApoA-1, apolipoprotein A-1.

Table 3. Correlations between serum CRP and serum lipids in outpatients.

\begin{tabular}{ccccccc}
\hline Compared variables & $\begin{array}{c}\text { Spearman } \mathrm{R} \\
\text { Women + Men } \\
(\mathrm{n}=2771)\end{array}$ & p-value & $\begin{array}{c}\text { Spearman R } \\
\text { Women } \\
(\mathrm{n}=1595)\end{array}$ & p-value & $\begin{array}{c}\text { Spearman R } \\
\text { Men } \\
(\mathrm{n}=1595)\end{array}$ & $\mathrm{p}$-value \\
\hline CRP and Triglycerides & 0.25 & $<0.001$ & 0.32 & $<0.001$ & 0.17 & $<0.001$ \\
CRP and ApoB/ApoA-1 ratio & 0.21 & $<0.001$ & 0.24 & $<0.001$ & 0.19 & $<0.001$ \\
CRP and HDL-cholesterol & -0.18 & $<0.001$ & -0.25 & $<0.001$ & -0.15 & $<0.001$ \\
CRP and ApoB & 0.18 & $<0.001$ & 0.18 & $<0.001$ & 0.17 & $<0.001$ \\
CRP and ApoA-1 & -0.11 & $<0.001$ & -0.14 & $<0.001$ & -0.09 & 0.002 \\
CRP and LDL-cholesterol & 0.07 & $<0.001$ & 0.06 & 0.01 & 0.08 & 0.006 \\
CRP and total cholesterol & 0.05 & 0.007 & 0.03 & 0.20 & 0.07 & 0.01 \\
CRP and Lp(a) & 0.04 & 0.03 & 0.05 & 0.04 & 0.03 & 0.32 \\
\hline
\end{tabular}

CRP, C-reactive protein; ApoB; apolipoprotein B; ApoA-1, apolipoprotein A-1. HDL, high density lipoprotein; LDL, low density lipoprotein; Lp(a), lipoprotein (a).

Table 4. Significant associations using stepwise regression analysis with log CRP as dependent variable.

\begin{tabular}{ccccc}
\hline Effect variables & $\begin{array}{c}\text { Log CRP } \\
\text { Beta* }^{*}\end{array}$ & $\begin{array}{c}-95 \% \\
\text { Confidence limit }\end{array}$ & $\begin{array}{c}+95 \% \\
\text { Confidence limit }\end{array}$ & p-value \\
\hline ApoB & 0.31 & 0.24 & 0.38 & $<0.001$ \\
Total cholesterol & -0.28 & -0.35 & -0.21 & $<0.001$ \\
Log Triglycerides & 0.16 & 0.12 & 0.20 & $<0.001$ \\
Log Lp(a) & 0.04 & 0.0054 & 0.078 & 0.02 \\
\hline
\end{tabular}

Independent variables included in the model were: log Lp(a), total cholesterol, log triglycerides, LDL-cholesterol, HDL-cholesterol, ApoA-1, ApoB and ApoB/ApoA-1 ratio. ApoB, total cholesterol, log triglycerides and log $\mathrm{Lp}(\mathrm{a})$ together explained $8 \%$ of the variation in log $\mathrm{CRP}$ (adjusted $\mathrm{R}^{2}=$ 0.078, $\mathrm{n}=2771$ ). ${ }^{*}$ Beta = the standardized regression coefficient. CRP, C-reactive protein; ApoB; apolipoprotein B; Lp(a), lipoprotein (a). 

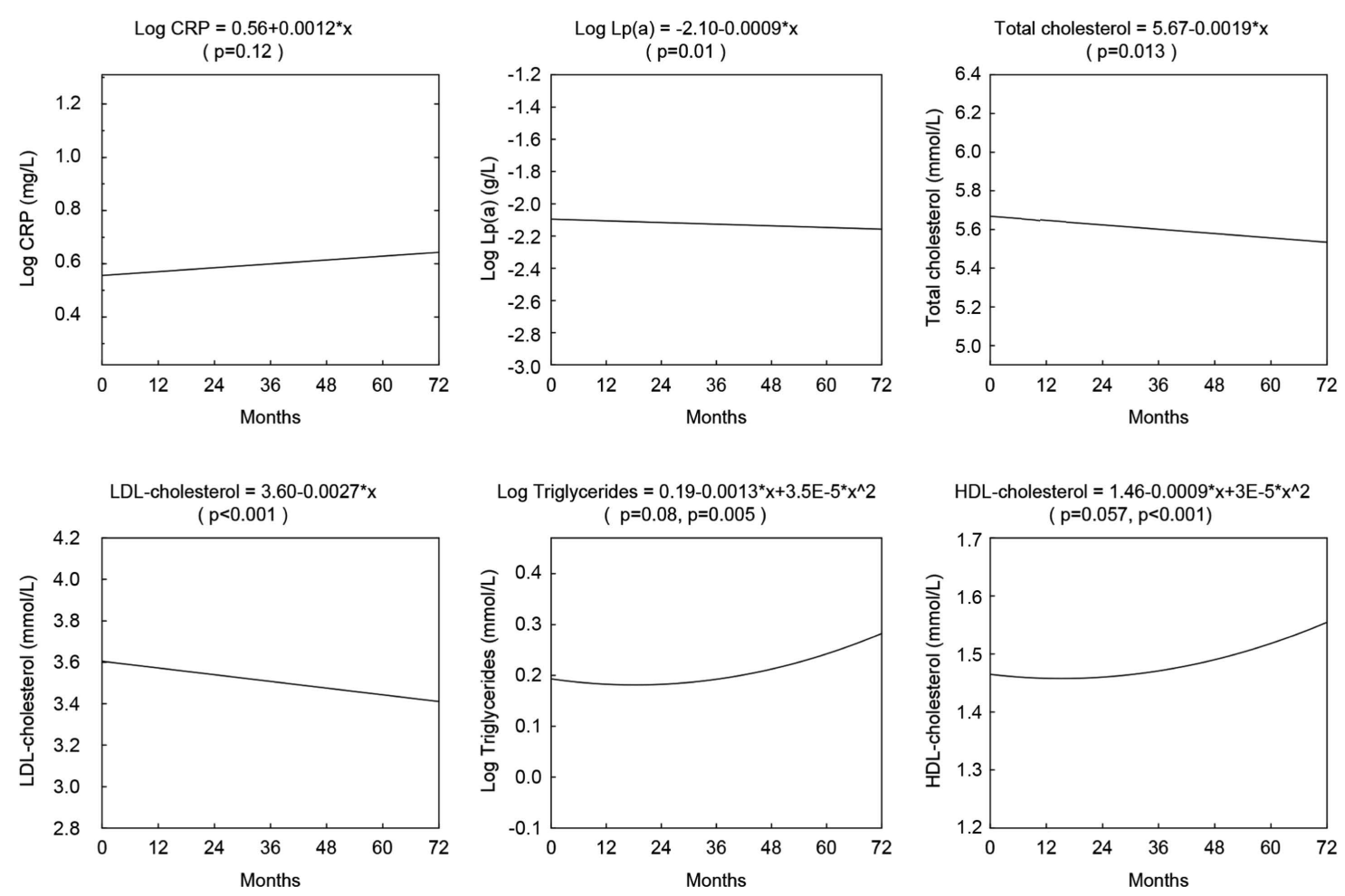

Log Triglycerides $=0.19-0.0013^{*} x+3.5 E-5^{\star} x^{\wedge} 2$

HDL-cholesterol $=1.46-0.0009^{*} x+3 E-5^{*} x^{\wedge} 2$
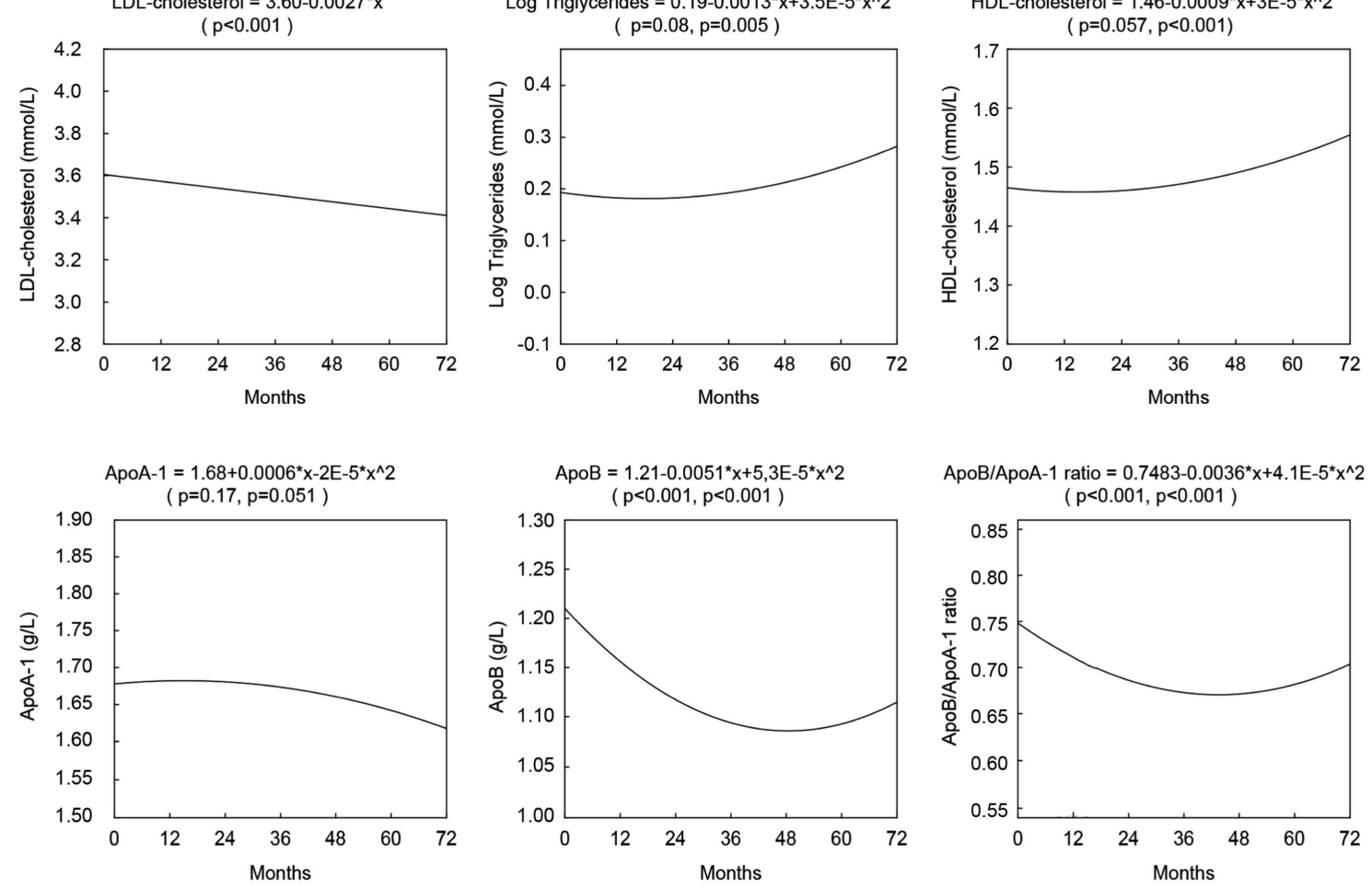

Figure 1. Intra-individual mean changes over time calculated by linear and non linear random coefficient models. First p-value refers to linear model and second p-value refers to non linear model. A maximum of seven time points were included in the model and the $\mathrm{x}$-axis shows number of months from first time point.

\section{Discussion}

The main finding was that serum CRP concentrations correlated stronger with lipid markers of the metabolic syndrome than with LDL-cholesterol. Whereas LDL-cholesterol levels changed in a favorable way with decreasing concentrations over time, CRP and triglycerides concentrations did not. The fact that CRP concentrations were unchanged or tended to increase in combination with increasing triglyceride levels and a trend of decreasing ApoA-1, may compromise other improvements in cardiovascular health. Such concerns have been raised for example regarding the increased prevalence of obesity in the northern Swedish population [7]. To the best of our knowledge there are no previously published studies on the association between CRP and a complete panel of lipids including, total cholesterol, triglycerides, LDL-cholesterol, HDL-cholesterol, ApoB, ApoA-1 and $\mathrm{Lp}(\mathrm{a})$, in an unselected population of outpatients in Swedish routine health care. In this study we used the combination of univariate correlation, stepwise regression analysis and time trend analysis to evaluate associations between CRP and lipid risk markers of CVD, and explored whether these risk markers changed in a favourable 
way for a population in routine health care. The results suggest a failure to reduce concentrations of the risk markers CRP and triglycerides over time.

\subsection{CRP versus Triglycerides}

Our finding that CRP correlates stronger with triglycerides than with other conventional lipid analyses is in agreement with findings in other large cohorts showing a significant association between CRP and triglycerides concentrations [8] [9]. The correlation between CRP and triglycerides was slightly stronger in woman then in men, which is in agreement with previous data [9]. The most consistence findings in the literature seem to be positive correlations between CRP, triglycerides and BMI and a negative correlation between CRP and HDLcholesterol in the healthy collective [10]-[12], suggesting a close relationship between low grade systemic inflammation and the metabolic syndrome. A similar pattern, with increased triglycerides and decreased HDLcholesterol concentrations, is an early and consistent metabolic alteration during infection/inflammation inducing an acute phase response [13]. Interestingly, a recent study on patients with combined hyperlipidemia showed a significant link between CRP metabolism and both triglyceride rich lipoprotein apoB-100 and triglyceride rich lipoprotein apoB-48 catabolism [14]. Correlations between CRP and serum lipids are generally weak and there are conflicting results in the literature. Furthermore most studies on outpatients are incomplete and do not include apolipoproteins and Lp(a). Our results add to previous reports suggesting that CRP correlates stronger with lipid markers of the metabolic syndrome than with other lipid markers in ambulatory outpatients.

\subsection{Time Trends}

One of the most important findings was the unfavourable time trends for CRP and triglycerides, counteracting a significant decrease in LDL-cholesterol and total cholesterol. This is in accordance with time trends for triglycerides, LDL-cholesterol and total cholesterol in the Northern Sweden MONICA population [7] [15]. A most plausible explanation for increasing triglycerides and CRP levels over time is the increasing prevalence of overweight and obesity in Sweden. For example in Stockholm County the prevalence of overweight an obesity increased significantly during the period 2002-2010, and the BMI values increased from mean 25.6 to 25.9 $\mathrm{kg} / \mathrm{m}^{2}$ for men and from 24.3 to $24.6 \mathrm{~kg} / \mathrm{m}^{2}$ for women from 2002 to 2010 (data available at:

http://www.folkhalsoguiden.se in FHr2011del6_Overvikt_web.pdf ). However, since we did not have access to patient files or other clinical data our hypotheses regarding correlations and time trends remain speculative. Another unfavourable trend that needs further studies was the significant increase of ApoB/ApoA-1 ratio seen at the end of the period. Since time trends for CRP and triglycerides differed from time trends for LDL-cholesterol and total cholesterol in the present study we conclude that CRP and triglycerides add information about cardiovascular risk in outpatients.

\subsection{CRP versus Cholesterol}

The correlation between CRP and total cholesterol was weak positive in univariate analysis but stronger and negative in multiple stepwise regression analysis. This somewhat unexpected finding is most likely explained by the fact that measurement of total cholesterol includes the fraction of cholesterol located in HDL particles and that there was a negative correlation between CRP and HDL-cholesterol in univariate regression analysis. Thus the negative correlation between CRP and total cholesterol in multivariate analysis may be caused, at least in part, by influence from HDL-cholesterol. HDL-cholesterol does not cause atherosclerosis. On the contrary, HDL lipoproteins have antiatherogenic properties and elevated HDL-cholesterol is associated with decreased CVD risk. Our findings underscore the limitation of total cholesterol alone as a marker of cardiovascular risk and the hazard of using total cholesterol as a single lipid marker for individual patients in risk calculators. Accordingly HDL-cholesterol has recently been added to the Systematic Coronary Risk Evaluation Project (SCORE) charts and electronic risk estimation systems [5]. Our finding of a very weak positive correlation between CRP and LDL-cholesterol is in agreement with other studies on large cohorts showing a minimal correlation coefficient of about 0.08 between CRP and LDL-cholesterol [16] [17] and between CRP and non-HDL-cholesterol [9].

\subsection{CRP versus Apolipoproteins}

In the present study not only triglycerides but also ApoB correlated stronger with CRP than total cholesterol and 
LDL-cholesterol did. One may speculate that a relatively high proportion of patients with the metabolic syndrome in unselected outpatients may explain that CRP correlates stronger with ApoB than with LDL-cholesterol. Patients with the metabolic syndrome have a discrepancy between LDL-cholesterol and ApoB concentrations depending on the many dense particles in the diseased group. In these patients LDL-cholesterol concentrations may be normal or only slightly elevated, whereas ApoB reflects the concentrations of particles, including small dense LDL that are supposed to be particularly atherogenic [18]. Therefore ApoB would be a better prognostic marker, and especially in patients with metabolic syndrome the ApoB/ApoA-1 ration is a powerful predictor of atherosclerotic disease [19]. It has been shown in unselected patients that traditional markers for hyperlipidemia do not forecast the results of measurements of the ApoB/ApoA-1 ratio with sufficient sensitivity and specificity [20]. Likewise in our study ApoB and the ApoB/ApoA-1 ratio added information compared with traditional lipids.

\subsection{CRP Versus Lp(a)}

Screening for elevated Lp(a) is suggested for patients at intermediate or high CVD risk [21]. However the effects of the inflammatory process on $\mathrm{Lp}(\mathrm{a})$ are unclear and seem to be population dependent. A strong positive correlation between CRP and Lp(a) concentrations was shown in rheumatoid arthritis patients [22] whereas in patients with type 2 diabetes mellitus no significant difference in CRP concentration was found comparing subjects with and without elevated Lp(a) [23]. In the present study on unselected outpatients there was a small but significant correlation between CRP and Lp(a), which is in accordance with findings of weak correlations between Lp(a) and several other known risk factors including CRP [24].

A limitation of the study design is the lack of clinical data which allows no analyses of subgroups of patients. Further studies using clinical data and chart review may reveal the reasons for the discrepant time trends shown in the present study. For example CRP associations with triglycerides, apoB, or HDL-cholesterol should be different between familial hypercholesterolemia, combined dyslipidemia, metabolic syndrome or patients with non alcoholic steatohepatitis. However, the main aim of the present study was to clarify the strength and independence of relationships between high sensitivity CRP and serum lipids in an unselected cohort of outpatients, and not to explore the causal relationship between these analytes. Combining random coefficients models and polynomials of time for linear and non-linear trends, as used in this study, may be a convenient way of visualizing changes over time for risk markers.

\section{Conclusion}

In conclusion, CRP correlated stronger with triglycerides and apolipoproteins than with LDL-cholesterol and Lp(a) in outpatients. LDL-cholesterol concentrations changed favourably over time whereas CRP and triglycerides did not.

\section{Acknowledgements}

We thank the biomedical scientists at the Department of Clinical Chemistry, Aleris Medilab, for excellent work.

\section{References}

[1] Pepys, M.B. and Hirschfield, G.M. (2003) C-Reactive Protein: A Critical Update. The Journal of Clinical Investigation, 111, 1805-1812. http://dx.doi.org/10.1172/JCI200318921

[2] Pearson, T.A., Mensah, G.A., Alexander, R.W., Anderson, J.L., Cannon 3rd, R.O., et al. (2003) Markers of Inflammation and Cardiovascular Disease: Application to Clinical and Public Health Practice: A Statement for Healthcare Professionals from the Centers for Disease Control and Prevention and the American Heart Association. Circulation, 107, 499-511. http://dx.doi.org/10.1161/01.CIR.0000052939.59093.45

[3] Quist-Paulsen, P. (2010) Statins and Inflammation: An Update. Current Opinion in Cardiology, 25, 399-405. http://dx.doi.org/10.1097/HCO.0b013e3283398e53

[4] Tsai, H.J. and Tsai, A.C. (2008) The Association of Plasma C-Reactive Protein Levels with Anthropometric and Lipid Parameters in Elderly Taiwanese. Asia Pacific Journal of Clinical Nutrition, 17, 651-656.

[5] Perk, J., De Backer, G., Gohlke, H., Graham, I., Reiner, Z., et al. (2012) European Guidelines on Cardiovascular Disease Prevention in Clinical Practice (Version 2012): The Fifth Joint Task Force of the European Society of Cardiology and Other Societies on Cardiovascular Disease Prevention in Clinical Practice (Constituted by Representatives of Nine Societies and by Invited Experts) * Developed with the Special Contribution of the European Association for Cardi- 
ovascular Prevention \& Rehabilitation (EACPR). European Heart Journal, 33, 1635-1701. http://dx.doi.org/10.1093/eurheartj/ehs092

[6] Kaptoge, S., Di Angelantonio, E., Pennells, L., Wood, A.M., White, I.R., et al. (2012) C-Reactive Protein, Fibrinogen, and Cardiovascular Disease Prediction. The New England Journal of Medicine, 367, 1310-1320. http://dx.doi.org/10.1056/NEJMoa1107477

[7] Eriksson, M., Holmgren, L., Janlert, U., Jansson, J.H., Lundblad, D., et al. (2011) Large Improvements in Major Cardiovascular Risk Factors in the Population of Northern Sweden: The MONICA Study 1986-2009. Journal of Internal Medicine, 269, 219-231. http://dx.doi.org/10.1111/j.1365-2796.2010.02312.x

[8] Danesh, J., Wheeler, J.G., Hirschfield, G.M., Eda, S., Eiriksdottir, G., et al. (2004) C-Reactive Protein and Other Circulating Markers of Inflammation in the Prediction of Coronary Heart Disease. The New England Journal of Medicine, 350, 1387-1397. http://dx.doi.org/10.1056/NEJMoa032804

[9] Kaptoge, S., Di Angelantonio, E., Lowe, G., Pepys, M.B., Thompson, S.G., et al. (2010) C-Reactive Protein Concentration and Risk of Coronary Heart Disease, Stroke, and Mortality: An Individual Participant Meta-Analysis. The Lancet, 375, 132-140. http://dx.doi.org/10.1016/S0140-6736(09)61717-7

[10] Buchbinder, S., Kratzsch, J., Fiedler, G.M., Yar, V., Brugel, M., et al. (2008) Body Weight and Oral Contraceptives Are the Most Important Modulators of Serum CRP Levels. Scandinavian Journal of Clinical \& Laboratory Investigation, 68, 140-144. http://dx.doi.org/10.1080/00365510701487727

[11] Lee, W.-Y., Park, J.-S., Noh, S.-Y., Rhee, E.-J., Sung, K.-C., et al. (2004) C-Reactive Protein Concentrations Are Related to Insulin Resistance and Metabolic Syndrome as Defined by the ATP III Report. International Journal of Cardiology, 97, 101-106. http://dx.doi.org/10.1016/j.ijcard.2003.08.016

[12] Ridker, P.M., Buring, J.E., Cook, N.R. and Rifai, N. (2003) C-Reactive Protein, the Metabolic Syndrome, and Risk of Incident Cardiovascular Events: An 8-Year Follow-Up of 14,719 Initially Healthy American Women. Circulation, 107, 391-397. http://dx.doi.org/10.1161/01.CIR.0000055014.62083.05

[13] Khovidhunkit, W., Kim, M.S., Memon, R.A., Shigenaga, J.K., Moser, A.H., et al. (2004) Effects of Infection and Inflammation on Lipid and Lipoprotein Metabolism: Mechanisms and Consequences to the Host. Journal of Lipid Research, 45, 1169-1196. http://dx.doi.org/10.1194/jlr.R300019-JLR200

[14] Thongtang, N., Diffenderfer, M.R., Ooi, E.M., Asztalos, B.F., Dolnikowski, G.G., et al. (2013) Linkage between C-Reactive Protein and Triglyceride-Rich Lipoprotein Metabolism. Metabolism, 62, 369-375. http://dx.doi.org/10.1016/j.metabol.2012.08.008

[15] Jansson, J.H., Boman, K. and Messner, T. (2003) Trends in Blood Pressure, Lipids, Lipoproteins and Glucose Metabolism in the Northern Sweden MONICA Project 1986-99. Scandinavian Journal of Public Health, 31, 43-50. http://dx.doi.org/10.1080/14034950310001397

[16] Backes, J.M., Howard, P.A. and Moriarty, P.M. (2004) Role of C-Reactive Protein in Cardiovascular Disease. Annals of Pharmacotherapy, 38, 110-118. http://dx.doi.org/10.1345/aph.1D203

[17] Ridker, P.M., Rifai, N., Rose, L., Buring, J.E. and Cook, N.R. (2002) Comparison of C-Reactive Protein and LowDensity Lipoprotein Cholesterol Levels in the Prediction of First Cardiovascular Events. New England Journal of Medicine, 347, 1557-1565. http://dx.doi.org/10.1056/NEJMoa021993

[18] Sniderman, A.D., Scantlebury, T. and Cianflone, K. (2001) Hypertriglyceridemic Hyperapob: The Unappreciated Atherogenic Dyslipoproteinemia in Type 2 Diabetes Mellitus. Annals of Internal Medicine, 135, 447-459. http://dx.doi.org/10.7326/0003-4819-135-6-200109180-00014

[19] Wallenfeldt, K., Bokemark, L., Wikstrand, J., Hulthe, J. and Fagerberg, B. (2004) Apolipoprotein B/Apolipoprotein AI in Relation to the Metabolic Syndrome and Change in Carotid Artery Intima-Media Thickness during 3 Years in Middle-Aged Men. Stroke, 35, 2248-2252. http://dx.doi.org/10.1161/01.STR.0000140629.65145.3c

[20] Estonius, M. and Kallner, A. (2005) How Do Conventional Markers of Lipid Disorders Compare with Apolipoproteins? Scandinavian Journal of Clinical Laboratory Investigation, 65, 33-44. http://dx.doi.org/10.1080/00365510510013497

[21] Nordestgaard, B.G., Chapman, M.J., Ray, K., Boren, J., Andreotti, F., et al. (2010) Lipoprotein(a) as a Cardiovascular Risk Factor: Current Status. European Heart Journal, 31, 2844-2853. http://dx.doi.org/10.1093/eurheartj/ehq386

[22] Dursunoglu, D., Evrengul, H., Polat, B., Tanriverdi, H., Cobankara, V., et al. (2005) Lp(a) Lipoprotein and Lipids in Patients with Rheumatoid Arthritis: Serum Levels and Relationship to Inflammation. Rheumatology International, 25, 241-245. http://dx.doi.org/10.1007/s00296-004-0438-0

[23] Ogbera, A.O. and Azenabor, A.O. (2010) Lipoprotein(a), C-Reactive Protein and Some Metabolic Cardiovascular Risk Factors in Type 2 DM. Diabetology Metabolic Syndrome, 2, 51. http://dx.doi.org/10.1186/1758-5996-2-51

[24] Erqou, S., Kaptoge, S., Perry, P.L., Di Angelantonio, E., Thompson, A., et al. (2009) Lipoprotein(a) Concentration and the Risk of Coronary Heart Disease, Stroke, and Nonvascular Mortality. Journal of the American Medical Association, 302, 412-423. http://dx.doi.org/10.1001/jama.2009.1063 